\title{
Oxygen regulator element to reduce the climate changes: the oxygen users must pay those who produce it
}

\author{
M. Hamdi
}

Published online: 7 April 2010

(C) Springer Science+Business Media B.V. 2010

\begin{abstract}
The climate warming reduction needs an approach based on a regulator element which links the ecological and economical goals. The ecosystem services have become less effective because the production of water and $\mathrm{CO}_{2}$ are faster than recycling it in biomass. The produced water with $\mathrm{CO}_{2}$, during the oxidation of organic carbon thanks to the chemical reduction of oxygen, is often neglected and not mentioned by the scientific community. The water volume that results from the burning of fossil fuels increases annually with $\mathrm{CO}_{2}$ emissions and is higher than thousands of billions of tons. This water increase affects water vapour levels and induces the risk of great floods and sea level rising. We suggest an ecolonomical (ecology and economy) integrative concept based on the use of oxygen, as a regulator, which links the burning of fuels that generate water and fossil $\mathrm{CO}_{2}$ to photosynthesis that regenerates oxygen and biomass essential for our life. The ecolonomical quantitative rule claims that the oxygen users such as transportation services, manufacturers and power plants must pay those who produce it such as forest, agriculture and urban vegetation. The application of this rule should induce the restoring
\end{abstract}

M. Hamdi $(\bowtie)$

Laboratory of Microbial Ecology and Technology,

Department of Biochemical and Chemical Engineering,

National Institute of Applied Sciences and Technology,

1080 Tunis, Tunisia

e-mail: moktar.hamdi@insat.rnu.tn of natural ecosystems and agricultural practices thanks to the link between the urban services and the rural services.

Keywords Climate change - Fossil carbon · Burning · Carbon dioxide - Oxygen .

Vapour water

\section{Introduction}

Urbanization has intensified the industrial and economic issues that have affected rural activities, natural resources, environment and biodiversity. Global demand for primary energy will increase by 55\% between 2005 and 2030. Hydrocarbons remain by far the primary source of energy. They represent $2 /$ 3 of global energy consumption and demand for oil should grow up by $37 \%$ by 2030 (IEA 2006; GIEC 2007). Demand for coal is expected to grow further by 2030 , while its share is expected to represent $28 \%$ of the global energy consumption. The use of fossil fuels, capitalizing $75 \%$ of greenhouse gas emissions, has caused global recent upheavals in climate and fuelled conversations on the warming caused by carbon dioxide (GIEC 2007). The technological development based on the high consumption of energy derived mainly from the burning of carbon fuels caused the unbalance of the carbon cycle. The unbalance between the organic carbon, carbon dioxide, oxygen and water is a great challenge to ensure 
sustainable development due to the biodiversity decline, the rising sea, the great floods and diseases propagation.

\section{Unbalance of the carbon cycle}

Solar energy remains the largest energy source for our planet. Through the anoxygenic and oxygenic photosynthesis, solar energy is stored in the form of organic molecules which are oxidized by all heterotrophic organisms. The photosynthesis allows maintaining the $\mathrm{CO}_{2}$ and oxygen concentrations in the atmosphere favourable to human and animal life. The primary production of energy in chemical form by photosynthetic organisms is estimated to $268 \mathrm{~mW} / \mathrm{m}^{2}$ and half of it is carried out in the oceans (Rosing et al. 2006). Photosynthesis is the key way to balance our planet because it allows an annual carbon fixation estimated to $9 \times 10^{15} \mathrm{~mol}$. However, photosynthesis is affected by the reduction of the photosynthetic organism and the availability of chemical elements such as phosphorus, nitrogen and iron (Rosing et al. 2006). The flow of mineral and organic carbon is controlled by photosynthetic organisms, which have been able to maintain a concentration of atmospheric $\mathrm{CO}_{2}$ constant at around $260 \mathrm{ppm}$ before the industrialization progress.

Thousands of $\mathrm{PgC}$ (petagram carbon) of stored organic carbon forms were stored and disconnected of the active carbon cycle. This form of organic carbon, also known as fossil carbon, was laid down over millions of years and suddenly all released within a period of a few hundred years. Actually, the organic carbon content in the biomass on land is estimated at $500 \mathrm{PgC}$ and in the soil at $200 \mathrm{PgC}$ (Janzen 2004). The increased burning of fossil fuels has raised the concentration of $\mathrm{CO}_{2}$ in the atmosphere and reduced the mass of carbon fixed in biomass through photosynthesis. The pool of atmospheric carbon is estimated at $785 \mathrm{PgC}$ (Janzen 2004). Moreover, the change in the conditions of agricultural crops has caused an annual increase of $\mathrm{CO}_{2}$ emissions, and the surface of the soil for agriculture has increased by around 30\% at the expense of forests and grasslands which have high capacity to sequester carbon.

Figure 1 clearly shows the unbalance between biomass, oxygen, water and $\mathrm{CO}_{2}$ because of the

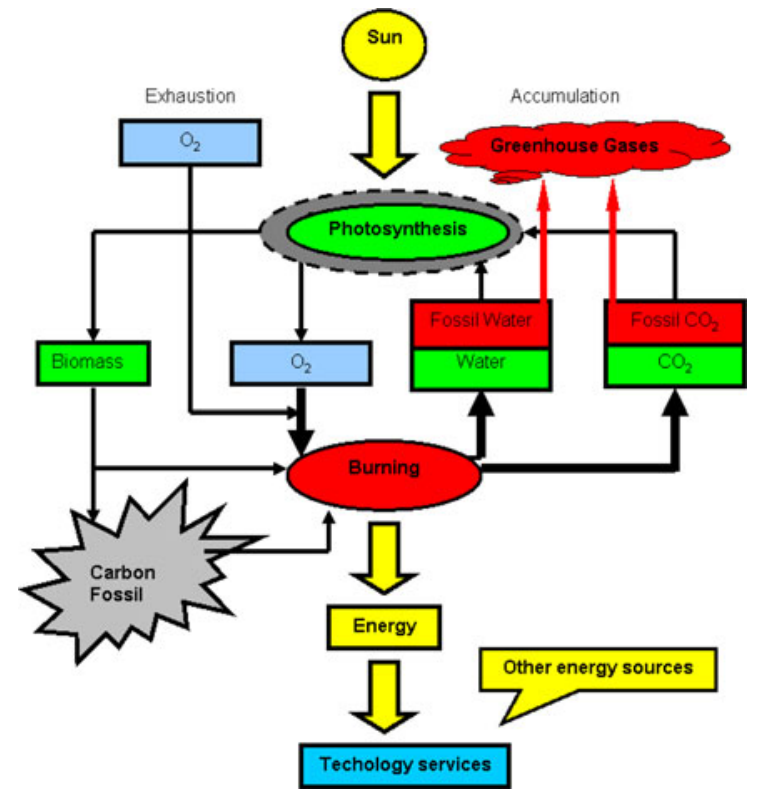

Fig. 1 Incidence of the altered photosynthesis and the fossil fuels burning on the unbalance between the biomass, oxygen, water and $\mathrm{CO}_{2}$ amounts

altered carbon cycle. The oxygen in the atmosphere decreases because the use of oxygen in burning and the alteration of the photosynthesis process. Indeed, the amount of oxygen dissolved in the oceans may decline, with adverse consequences for ocean life (Shaffer et al. 2009). The emission of carbon from the burning of fossil fuels has resulted in an increase in the concentration of $\mathrm{CO}_{2}$ in the atmosphere from 260 to $370 \mathrm{ppm}$ (Janzen 2004). The $\mathrm{CO}_{2}$ is the main greenhouse gas causing climate changes, great floods, rising sea levels, and spread of devastating diseases.

The water produced with $\mathrm{CO}_{2}$, during the oxidation of organic carbon thanks to the chemical reduction of oxygen, is often neglected and not mentioned by the scientific community. The rising seas causing loss of coastal lands, is generally attributed to the climate change. However, one should consider water produced by the fuels burning and also water accumulated because of the affected oxygenic photosynthetic which cleaves water. The water volume that results from the burning of fossil fuels increases annually with $\mathrm{CO}_{2}$ emissions (Janzen 2004; Nakicenovic et al. 2000) and is higher than thousands of billions of tons (Fig. 2). The ratio of the $\mathrm{CO}_{2}$ emission and water produced during the fossil fuel burning depends on the nature of the source of 


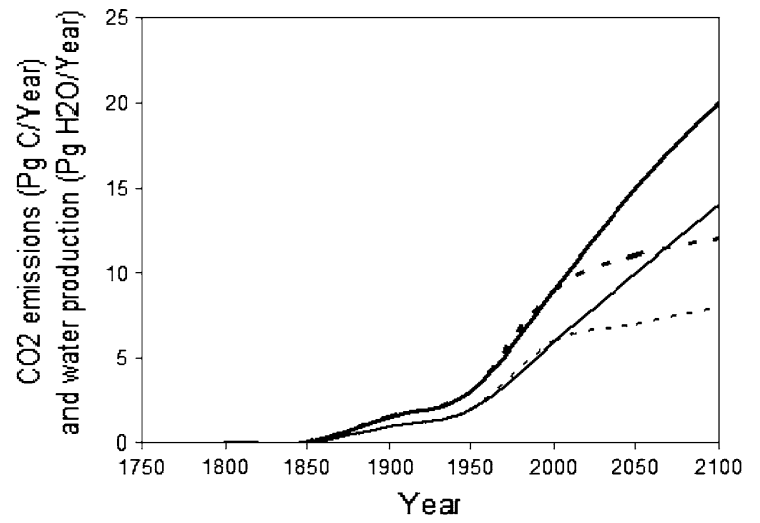

Fig. 2 Estimated and predicted water productions from fossil fuel burning without (-) and with (- - ) application of the oxygen managerial system, according the $\mathrm{CO}_{2}$ emissions (Janzen 2004; Nakicenovic et al. 2000) without (-) and with (- - ) application of the oxygen managerial system

energy used. This water increase affects water vapour levels and induces the risk of great floods (Milly et al. 2002). Indeed, the effect of water vapor is strong enough to double the climate warming caused by increased levels of carbon dioxide in the atmosphere (Dessler et al. 2008). Water vapour affects also the water transport in plants and then their growth rate and production, as mentioned recently by Lendzion and Leuschner (2008).

\section{Oxygen managerial system}

The unbalance between the organic carbon, oxygen, fossil carbon dioxide and water will widen as energy consumption triples by 2055 . This may be considered as a great challenge to ensure sustainable development. The energy needs for mankind are enormous and in a huge continuous progress. In fact, it contributes massively to the climate change in the absence of new measures taken for global energy consumption limitation. The international energy agency (IEA) reported the possible pathway for reducing global $\mathrm{CO}_{2}$ emission in many economical sectors and manufactures (IEA 2008). The climate warming reduction needs an approach based on a regulator element, which links the ecological and economical goals. The ecosystem services are increasingly affected by the pollution resulting from the fossil energy burning and other economical

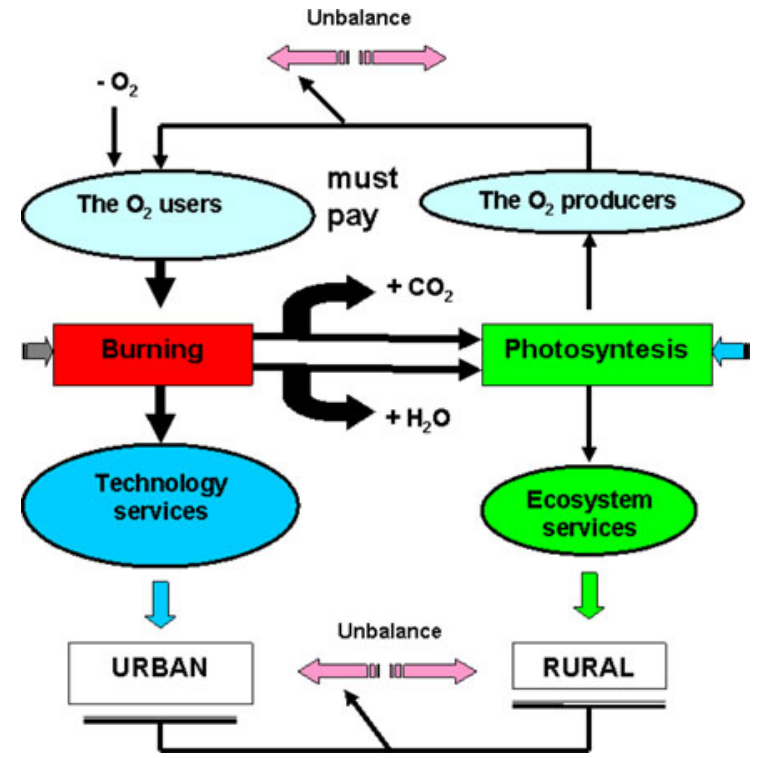

Fig. 3 The unbalance between the ecosystem services and the technology services and its impacts on the $\mathrm{CO}_{2}$ and water accumulation

activities. Changes in biodiversity are currently the fastest in the history of mankind.

The species extinction rates are currently 1001,000 times than the pre-human rate (Pimm et al. 1995). Currently, food is based on only thirty plant and animal species that have the highest productivity. The increased productivity of food does not go hand in hand with the growing population, which is expected to stabilize at 12 billions at the end of the actual century. The ecosystems have become less effective because the production of water and $\mathrm{CO}_{2}$ are faster than their recycling in biomass (Fig. 3). The ecosystem services are affected differently in countries depending on the level of technological development. The needs of the citizens of the planet in terms of floor space (ecosystem services) can reach $8 \mathrm{ha} /$ person in developed countries. Ecosystems are relatively protected in many countries by intensive systems of management and treatment of wastes. However, the current pollution control systems are not always in favour of restoring the carbon cycle because their high energy consumption and organic carbon mineralization. The ecosystem management and use of energy needed to human activity require a new ecopolicy based on the integrative concept to reduce the climate change. Current economical development systems involve two opposing systems: 
Table 1 Integration of technology in the nature

\begin{tabular}{llll}
\hline Criteria & Ecosystems & Technology & Ecotechnology \\
\hline Unity & Cell & Process & Integrated bioprocess \\
Goal & Sustainable & Productivity & Sustainable productivity \\
Activity & Biodiversity: parallel and serial & Specialization: intensive & Alternation between smooth and intensive \\
& smooth activity & serial activity & activity \\
State system & Open: stationary state & Closed: transitory state & Connected closed system: open system \\
Management & Cooperative and conservative & Competitive and innovative & Sustainable innovation and cooperation \\
Landscape & Continuous & Fragmentation & Integration of technology in the nature: \\
& & & Compartment evolution \\
Energy & Photosynthesis: hydrogen & Burning: $\mathrm{CO}_{2}$ and water & Green energy and clean energy sources \\
Pollution & and carbon sequestration & production & Coupling production and recycling \\
Human density & Recycling & Production & Rural exodus reverse \\
Location & Rural & High & Coupling rural and urban services \\
\hline
\end{tabular}

ecology services and technology services which do not have the same goals and are based on different management approaches (Table 1). A consensus between the majority of scientists reveals that climate change comes mainly from large anthropogenic emissions of greenhouse gases (GIEC 2007; Janzen 2004), and water vapour (Dessler et al. 2008).

There are ways to reduce the annual emission of $\mathrm{CO}_{2}$ and water vapour in the atmosphere while keeping up with increasing energy needs. The first solution would be to replace the maximum fossil fuels by biofuels (ethanol and biogas) which are made of sequestered carbon issued from the photosynthesis. This has the advantage of eliminating the $\mathrm{CO}_{2}$ from the atmosphere and recycling it into biofuels. The second route would be to reduce $\mathrm{CO}_{2}$ emissions by using clean energy sources such as solar, wind and nuclear sources (IEA 2008). The third way is based on improving the phenomena of $\mathrm{CO}_{2}$ storage in biomass improving photosynthesis and reducing the activities of mineralization of organic carbon in ecosystems and promoting the natural carbon capture and storage. The approach that integrates the three ways is the most promising because it produces biofuels, will help restoring the altered carbon cycle and improve the ecosystem services as food production and wastes recycling. However, the mechanisms that allow the connection between sound climate change and maintained development policies for sustainable growth require an innovative and integrative thought. The measures taken to attenuate the climate change impacts on the planet based on the $\mathrm{CO}_{2}$ emissions reduction seems a partial solution for ecosystems restoring because the economical actors are not directly involved.

An ecolonomical (integrating ecology and economy) approach is needed to help restoring the ecosystem services and promoting green economic development. We suggest an integrative concept based on the use of oxygen as a regulator which links the burning of fuels that generate water and $\mathrm{CO}_{2}$ with the photosynthesis process that regenerates oxygen and biomass essential for our life (Fig. 3). The ecolonomical quantitative rule claims that the oxygen users such as transportation services, manufacturers and power plants must pay those who produce it such as forest, agriculture and urban vegetation. The application of this rule will contribute in the reduction of the $\mathrm{CO}_{2}$ emissions and water accumulation (Fig. 2), in spite of the growth of the global energy consumption by the burning of the fuels according the Special Report on Emission Scenarios (Nakicenovic et al. 2000).

The proposed oxygen managerial system should induce the restoring of natural ecosystems and agricultural practices because it allows the coupling of the technology and ecosystems and links between the urban services and the rural services (Table 1). The urban-rural conflicts became a real challenge because of the unbalance between both areas, which need to be addressed urgently in some regions in Africa and Asia to a change in development policies. 
In fact, the econometric analysis suggested that climatic change has acted to change urbanization in sub-Saharan Africa because the intensified decolonization of agricultural areas, but not elsewhere in the developing world (Barrios et al. 2006). The risk perception and perceived adaptive capacity of urban and rural persons are largely neglected in previous climate change (Grothmann and Patt 2005). The multidisciplinary integrative of knowledge and sustainable uses of natural sciences and technologies, economics, and social sciences are required for an effective ecosystem management (UNEP-CBD 1998).

\section{Conclusion}

The water volume, that results from the burning of fossil fuels increases annually with $\mathrm{CO}_{2}$ emissions and is higher than thousands of billions of tons, is often neglected and not mentioned by the scientific community. This water increase affects water vapour levels and induces the risk of great flooding and sea level rising. The climate warming reduction needs an approach based on a regulator element which links the ecological and economical goals.

We suggest an ecolonomical quantitative rule which claims that the oxygen users such as transportation services, manufacturers and power plants must pay those who produce it such as forest, agriculture and urban vegetation.

The application of this rule should induce the restoring of natural ecosystems and agricultural practices thanks to the link between the urban services and the rural services.

\section{References}

Nakicenovic N et al. (2000) Special report on emissions scenarios. Cambridge University Press. http://unep.no/climate/ ipcc/emission/index.htm

Dessler AE, Zhang Z, Yang P (2008) Water-vapor climate feedback inferred from climate fluctuations, 2003-2008. Geophys Res Lett 35:333-339

Grothmann T, Patt A (2005) Adaptive capacity and human cognition: the process of individual adaptation to climate change. Global Environ Change 15:199-213

IEA (International Energy Agency) (2006) World Energy Outlook 2006 www.iea.org

IEA (International Energy Agency) (2008) Energy technology perspective 2008. Organization for Economic Cooperation and Development, Paris

Janzen HH (2004) Carbon cycling in earth systems-a soil science perspective. Agri Ecosyst Environ 104:399-417

Lendzion J, Leuschner C (2008) Growth of European beech (Fagus sylvatica L.) saplings is limited by elevated atmospheric vapour pressure deficits. Forest Ecol Manage 256:648-655

Milly PCD, Wetherald RT, Dunne KA, Delworth TL (2002) Increasing risk of great floods in a changing climate. Nature 415:514-517

Pimm SL, Russell GJ, Gittleman JL, Brooks T (1995) The future of biodiversity. Science 269:347-350

Report-GIEC (2007) http://www.effet-de serre.gouv.fr/fr/etudes/ SPM2007gr1.doc

Rosing TM, Bird DK, Sleep NM, Glassle WF, Albarede F (2006) The rise of continets-an essay on the consequences of geologic photosynthesis. Palaeogeogr Palaeoclimatol Palaeoecol 232:99-113

Shaffer G, Olsen SM, Pedersen JOP (2009) Long-term ocean oxygen depletion in response to carbon dioxide emissions from fossil fuels. Nat Geosci 2:105-109

UNEP/CBD/COP/4/Inf.9 (1998) Report of the workshop on the ecosystem approach 